\title{
Aleitamento materno: Conhecimento prévio de adolescentes nulíparas
}

\section{Breastfeeding: Preliminary knowledge of nulliparous teenagers}

DOI: $10.46919 / \operatorname{archv} 2 \mathrm{n} 2-004$

Recebimento dos originais: 01/01/2021

Aceitação para publicação: 31/03/2021

\author{
Elaine Andréa Ramos Lima \\ Graduada em Medicina \\ Instituição: Universidade Tiradentes (UNIT) \\ Endereço Institucional: Av. Murilo Dantas, 300 - Farolândia, Aracaju - SE \\ E-mail: naniandrear@hotmail.com \\ Alberto Calson Alves Vieira \\ Acadêmico de Medicina \\ Instituição: Universidade Tiradentes (UNIT) \\ Endereço Institucional: Av. Murilo Dantas, 300 - Farolândia, Aracaju - SE \\ E-mail: albertocalson@hotmail.com \\ Halley Ferraro Oliveira \\ Doutorado em andamento em Ciências da Saúde \\ Instituição: Universidade Tiradentes (UNIT) \\ Endereço Institucional: Av. Murilo Dantas, 300 - Farolândia, Aracaju - SE \\ E-mail: halleyoliveira@yahoo.com.br \\ Ana Jovina Barreto Bispo \\ Doutora em Ciências da Saúde \\ Instituição: Universidade Tiradentes (UNIT) \\ Endereço Institucional: Av. Murilo Dantas, 300 - Farolândia, Aracaju - SE \\ E-mail: anajovina70@gmail.com \\ Izailza Matos Dantas Lopes \\ Doutorado em andamento em Saúde e Ambiente \\ Instituição: Universidade Tiradentes (UNIT) \\ Endereço Institucional: Av. Murilo Dantas, 300 - Farolândia, Aracaju - SE \\ E-mail: izailzamatos@gmail.com
}

\section{RESUMO}

Introdução: O Ministério da Saúde (MS) define o Aleitamento Materno Exclusivo (AME) como a alimentação do recém-nato com leite materno, diretamente do seio ou ordenhado, sem acréscimo de outros alimentos artificiais, água, chupeta ou mamadeira. O AM promove uma oferta adequada e essencial de nutrientes para o crescimento e desenvolvimento das crianças, além de proteger contra infecções e outras doenças, aumentando as chances de sobrevida. Objetivo: Avaliar o conhecimento prévio de adolescentes nulíparas sobre o Aleitamento materno. Metodologia: Pesquisa transversal, analítica, descritiva, com abordagem qualitativa. O universo do estudo foi composto por 107 estudantes do sexo feminino de duas escolas do município de Aracaju/ SE. Para a coleta de dados foi utilizado um questionário elaborado pelo autor baseado na literatura. Resultados: Observou-se que 81,3\% conheciam a definição de aleitamento materno. Todas $(100 \%)$ consideraram que o leite materno é importante para o desenvolvimento do bebê. O 
tempo mínimo de amamentação exclusiva mais assinalado pelas adolescentes foi o intervalo entre 3 a 6 meses (52,3\%). Além disso, 81,3\% referiram que existe leite materno fraco e 67,3\% alegaram que a amamentação pode levar a queda dos seios. Em relação a alimentação complementar, $85 \%$ das participantes ressaltaram que o "gogó", ou seja, as fórmulas prontas, alimenta mais a criança que o leite materno e apenas, 36,4\% sinalizaram que a mamadeira e a chupeta atrapalham a amamentação. Conclusão: Concluiu-se que é necessário intervenções efetivas em ambiente escolar, a fim de promover a futura prática do aleitamento materno.

Palavras-chave: Adolescência; Aleitamento materno; Alimentação complementar.

\begin{abstract}
Introduction: The Ministry of Health $(\mathrm{MOH})$ defines exclusive breastfeeding as the feeding of the newborn with breast milk, directly from the breast or milk, without the addition of other artificial foods, water, pacifiers or bottles. AM promotes an adequate and essential supply of nutrients for the growth and development of children, and protects against infections and other diseases, increasing the chances of survival. Objective: To evaluate the prior knowledge of nulliparous adolescents about breastfeeding. Methodology: Cross-sectional, analytical, descriptive research with a qualitative approach. The study population was composed of 107 female students from two schools in the city of Aracaju / SE. For data collection, a questionnaire elaborated by the author based on the literature was used. Results: it was observed that $81.3 \%$ knew the definition of breastfeeding. All $(100 \%)$ considered that breast milk is important for the development of the baby. The minimum time of exclusive breastfeeding most marked by the adolescents was the interval between 3 to 6 months (52.3\%). In addition, 81.3\% reported weak breast milk and $67.3 \%$ reported breastfeeding may lead to breast reduction. Regarding complementary feeding, $85 \%$ of the participants pointed out that the "gogó", that is, the ready formulas, fed the child more than the mother's milk, and only $36.4 \%$ indicated that the bottle and the pacifier interfere with breastfeeding. Conclusion: It was concluded that effective interventions are necessary in school environment, in order to promote the future practice of breastfeeding.
\end{abstract}

Keywords: Adolescence; Breastfeeding; Complementary feeding.

\title{
1 INTRODUÇÃO
}

O Ministério da Saúde (MS) define o Aleitamento Materno Exclusivo (AME) como a alimentação do recém-nato com leite materno, diretamente do seio ou ordenhado, sem acréscimo de outros alimentos artificiais, água, chupeta ou mamadeira ${ }^{1,2}$. O AM promove uma oferta adequada e essencial de nutrientes para o crescimento e desenvolvimento das crianças, além de proteger contra infecções e outras doenças, aumentando as chances de sobrevida. Apesar do conhecimento dos benefícios ainda existem elevadas taxas de desmame precoce em nosso país.

De acordo com a II Pesquisa de Prevalência de Aleitamento Materno nas Capitais Brasileiras e Distrito Federal (2008/2009), no contexto nacional, a taxa de aleitamento exclusivo durante os 6 (seis) primeiros meses de vida foi de $41 \%$. Distribuída entre as regiões Norte com 45,9\%, Centro-Oeste 45\%, Sul $43,9 \%$, Sudeste com 39,4\% e Nordeste com $37 \%^{3}$. Essas taxas estão longe da desejada pela OMS que seria de $100 \%$ nos primeiros 6 meses $^{4}$. Vale ressaltar que o desmame precoce está intimamente relacionado ao 
aumento das taxas de morbimortalidade infantil, por isso, é fundamental tentar desencorajá-lo. Além disso, em países em desenvolvimento, como é o caso do Brasil, a prática do aleitamento tem extrema importância social, particularmente quando voltada para as classes com condições socioeconômicas menos favorecidas ${ }^{5}$.

No Brasil, a taxa de gravidez na adolescência ainda é elevada. Segundo dados do IBGE cerca de 19,3\% das crianças nascidas vivas em 2010 são filhos e filhas de mulheres de 19 anos ou menos. E, esse grupo é considerado de risco para o desmame precoce.

A mãe adolescente traz consigo situações conflitantes desse período e, por vezes, não se sentem capazes psicologicamente, tampouco emocionalmente para assumir tal responsabilidade ${ }^{6}$. Por isso, essa fase constitui-se um fator de risco para o sucesso da amamentação, principalmente se a nutriz não possuir um conhecimento prévio efetivo sobre essa prática.

Diante do exposto, se faz necessário a conscientização de adolescentes nulíparas sobre o Aleitamento Materno, desde a sua fisiologia até as vantagens que esse ato pode trazer para a mãe, o bebê e a sociedade, pois, o conhecimento da mãe é um dos fatores que interfere nas decisões da amamentação, desmame e alimentação infantil. Além disso, essas adolescentes serão futuras disseminadoras de informação, desmistificando alguns pontos intrínsecos em nossa cultura, porém errôneos sobre o Aleitamento.

\section{METODOLOGIA}

Trata-se de um estudo transversal, analítico, descritivo, com abordagem qualitativa. O universo foi composto por estudantes do sexo feminino de duas escolas do município de Aracaju/ SE.

Os locais que serão utilizados para a realização da pesquisa são: Uma escola particular que oferece o ensino do maternal ao ensino médio e uma instituição de ensino pública que dispõe somente das séries do ensino médio. O número de alunos matriculados no ensino médio no ano de 2018 do colégio particular é de 297, sendo que 178 são do sexo feminino. Já o número de alunos matriculados no ano de 2018 na escola pública é de 952, desses, 514 são estudantes do sexo feminino.

Para a quantidade de amostra total de participantes, foi obtido com a coordenação das respectivas escolas que há 692 alunas matriculadas regularmente no ano de 2018. Foi calculada uma amostra, considerando um erro de 5\%, um nível de confiança de 95\%, resultando em uma amostra mínima de 115 adolescentes. Para a realização desse cálculo foi considerada uma população finita de 200, desvio padrão de 0,3 (alfa), Z (variável normal padronizada associada ao nível de confiança =1,96) e o erro amostral de 0,05 (E). Para encontrar o $\mathrm{n}$ da população infinita multiplicou-se o $\mathrm{Z}^{2}$ por alfa ${ }^{2}$ e dividido por $\mathrm{E}^{2}$ $(3,841 \times 0,09 / 0,0025)$ encontrando o valor de 138. No cálculo da população finita foi multiplicado o $\mathrm{n}$ da população infinita pelo $\mathrm{N}$ da população finita e dividido pelo $\mathrm{n}$ da população infinita somado com a 
população finita $(692 \times 138 / 692+138)$ encontrando o $n$ amostral da pesquisa que será de 115 adolescentes nulíparas.

A população corresponde a alunas maiores de 10 anos que estejam matriculadas regularmente na escola pesquisada.

Serão incluídas no estudo as estudantes maiores de 10 anos, do sexo feminino, nulíparas, orientadas, que possuam a capacidade de compreensão das perguntas expostas no questionário e que assinem o Termo de Consentimento Livre e Esclarecido (TCLE) ou que estejam devidamente autorizadas pelos responsáveis (em caso de menores de 18 anos).

Serão excluídas do estudo, as alunas que apresentem doença física ou mental que as limitem na compreensão das perguntas ou respostas, as não autorizadas pelos responsáveis, que já tiveram filho ou que se recusem a participar da pesquisa.

Os sujeitos selecionados responderam um questionário autoaplicável, com perguntas abertas e fechadas sobre o perfil sociodemográfico e conhecimento prévio sobre Aleitamento materno. Esse questionário foi elaborado pelo pesquisador, baseado na literatura. Em sua elaboração, os riscos foram minimizados, mas, é possível que a estudante possa se sentir constrangida mediante o teor da questão e/ou desconfortável pelo tempo que se colocará disponível para preencher os instrumentos da pesquisa. Além disso pode ter desconforto de ser identificada. Entretanto elas serão codificadas por números para minimizar ao máximo esse risco.

Inicialmente, o pesquisador responsável foi nas escolas para apresentar o projeto aos coordenadores de cada instituição. Em seguida, após a autorização dos coordenadores, o pesquisador foi nas salas de aula para explicar as alunas no que consiste a pesquisa e assim, distribuir os termos de autorização/ consentimento. Em um segundo momento, em ambiente propício, os questionários foram aplicados as participantes que entregarem o Termo de Assentimento Livre e Esclarecido (TALE) assinado por seus respectivos responsáveis ou o TCLE.

Os dados foram analisados e interpretados utilizando a estatística descritiva e inferencial. As variáveis categóricas serão apresentadas por meio de frequências simples e relativas com intervalos de confiança. Na parte inferencial, será utilizado o teste qui-quadrado e o teste exato de Fisher, quando mais adequado para descobrir associações entre as variáveis. Para a variável numérica será utilizado o teste t para amostras independentes. O nível de significância estatística estipulado será de $5 \%(\mathrm{p} \leq 0,05)$ e todos os testes serão bicaudais. O software utilizado para as análises será o Statistical Package for the Social Sciences (IBM SPSS 21.0).

Para o levantamento bibliográfico, foram utilizados os bancos de dados Literatura LatinoAmericana e do Caribe em Ciências da Saúde (LILACS), National Library of Medicine (PubMed), 
Scientific Electronic Library Online (SCIELO) e Biblioteca Virtual em Saúde Aleitamento Materno (BVS$\mathrm{AM})$.

Este estudo está de acordo com a Resolução no 196/96 do Conselho Nacional de Saúde e foi aprovado pela Comissão de Ética em Pesquisa da Universidade Tiradentes (CEP-UNIT) conforme o protocolo CAEE $n^{\circ}$ 86170418.9.0000.5371, enviado dia 26/03/2018. As informações colhidas foram mantidas em sigilo e foram utilizadas única e exclusivamente para a confecção deste trabalho. Não houve conflito de interesses na elaboração do estudo.

\subsection{DEFINIÇÕES IMPORTANTES}

Aleitamento materno (AM):

O aleitamento materno (AM) é importante, uma vez que o lactente é suprido com o leite da mãe (direto da mama ou ordenhado), independentemente de receber ou não outros alimentos ${ }^{1,2}$.

Aleitamento materno predominante (AMP):

O aleitamento materno predominante é quando a dieta da criança é composta pelo leite materno, como principal fonte nutricional, acrescido de água ou líquidos à base de água (água adocicada, chás, infusões), sucos de frutas e fluidos rituais ${ }^{1,2}$.

Aleitamento materno complementado (AMC):

O aleitamento materno complementado, como o nome já diz, possui a finalidade de complementação do leite materno, é introduzido no cardápio nutricional da criança alimentos semi sólidos ou sólidos ${ }^{1,2}$.

Aleitamento materno misto ou parcial (AMM):

Além do leite materno, é ofertado ao lactente outros tipos de leite.

A OMS e o MS orientam que a dieta da criança seja composta por leite materno exclusivo nos primeiros seis meses de vida, permanecendo complementado por outras fontes alimentares até os dois anos ou mais. A introdução de alimentos complementares antes dos seis meses pode ocasionar prejuízos à saúde do bebê, por isso não é recomendada ${ }^{1,2}$.

Com a finalidade de incentivar as mães a estabelecerem a amamentação exclusiva por seis meses para os seus filhos, a OMS e o Fundo das Nações Unidas para a Infância (UNICEF) orientam que a criança já comece a mamar na primeira hora de vida, sob demanda espontânea. Além disso, não é necessário o acréscimo de nenhuma outra fonte alimentar, nem mesmo água e também não há necessidade do uso de bicos, chupetas ou garrafas. 


\subsection{DESMAME PRECOCE}

O desmame precoce é definido como a cessação da prática de amamentação exclusiva com a substituição total ou parcial do leite materno por outras fontes nutricionais antes do lactente completar os seis meses de idade, acarretando a deficiência de elementos essenciais do leite materno o que pode levar a prejuízos na saúde da nutriz e da criança ${ }^{7}$.

\section{JUSTIFICATIVA E OBJETIVOS}

A amamentação é um tema bastante discutido entre as gestantes, porém ainda pouco abordado entre as nulíparas. Esse trabalho foi realizado com o intuito de avaliar o conhecimento prévio de adolescentes nulíparas sobre quais os benefícios para a mãe, o bebê e a sociedade a prática da Lactação pode trazer. O estudo visa também traçar o perfil sociodemográfico e correlacioná-lo ao conhecimento que a participante terá acerca do tema abordado. Além disso, espera-se que haja um incentivo a busca de informação e discussões sobre o Aleitamento materno dentro do grupo estudado e, por conseguinte, estimular a futura prática do mesmo.

\section{RESULTADOS}

Das 115 (cento e quinze) estudantes abordadas pelo pesquisador, apenas 107 participaram do estudo de forma efetiva, pois 1 (uma) já havia ficado grávida e as outras 8 (oito) eram menores de idade e não levaram os Termos de Assentimento devidamente assinados. As características socioeconômicas das participantes estão descritas na Tabela 1, as quais 54 pertenciam a escola particular e 53 a escola pública.

A maioria das adolescentes pertencia à faixa etária de 16 a 18 anos (59,8\%), declararam-se de etnia parda (54,2\%), nasceram na capital do Estado (82,2\%) e eram solteiras $(97,2 \%)$. Apenas $1(0,9 \%)$ referiu ter atividade laboral remunerada. A maior parte das estudantes afirmou residirem com os pais $(98,1 \%)$ e a renda familiar mensal mais prevalente foi de até 02 salários mínimos $(47,7 \%)$. Em relação a escolaridade, a conclusão do ensino fundamental foi predominantemente em escola particular (48,6\%).

Tabela 1 - Características sociodemográficas de adolescentes nulíparas de duas escolas do município de Aracaju - SE, 2018.

\begin{tabular}{|c|c|c|}
\hline Variáveis & N & \% \\
\hline Faixa etária (anos) & & 40,2 \\
\hline 13 a 15 & 43 & 59,8 \\
\hline 16 a 18 & 64 & \\
\hline Etnia & & 25,2 \\
\hline Branca & 27 & 54,2 \\
\hline Parda & 58 & \\
\hline
\end{tabular}




\begin{tabular}{|c|c|c|}
\hline Negra & 7 & 6,5 \\
\hline Amarela & 14 & 13,1 \\
\hline Indígena & 1 & 0,9 \\
\hline \multicolumn{3}{|l|}{ Onde nasceu } \\
\hline Aracaju (capital) & 89 & 82,2 \\
\hline Interior & 7 & 6,5 \\
\hline Outro Estado & 12 & 11,2 \\
\hline \multicolumn{3}{|l|}{ Estado Civil } \\
\hline Solteira & 104 & 97,2 \\
\hline União estável & 3 & 2,8 \\
\hline \multicolumn{3}{|l|}{ Moradia } \\
\hline Com os pais & 105 & 98,1 \\
\hline Sozinho & 1 & 0,9 \\
\hline Com outros familiares & 1 & 0,9 \\
\hline \multicolumn{3}{|l|}{ Ocupação } \\
\hline Sem trabalho remunerado & 106 & 99,9 \\
\hline Com trabalho remunerado & 1 & 0,9 \\
\hline \multicolumn{3}{|l|}{ Ensino Fundamental } \\
\hline Todo em pública & 12 & 11,2 \\
\hline Particular com bolsa & 11 & 10,3 \\
\hline Maior parte em particular & 19 & 17,8 \\
\hline Maior parte em pública & 11 & 10,3 \\
\hline $\begin{array}{l}\text { Maior parte em particular com } \\
\text { bolsa }\end{array}$ & 2 & 1,9 \\
\hline Todo em particular & 52 & 48,6 \\
\hline
\end{tabular}

$\mathrm{N}=$ Número de adolescentes.

$\%=$ Porcentagem do número de adolescentes.

Fonte: banco de dados do próprio autor

Em relação aos conhecimentos prévios que as entrevistadas possuíam sobre a amamentação, expostos na Tabela 2, observou-se que 81,3\% conheciam a definição de aleitamento materno. Todas (100\%) consideraram que o leite materno é importante para o desenvolvimento do bebê. O tempo mínimo de amamentação exclusiva mais assinalado pelas adolescentes foi o intervalo entre 3 a 6 meses (52,3\%). Vale ressaltar que $91,6 \%$ das participantes foi amamentada quando criança e o tempo médio referido foi de aproximadamente 18 meses. 
Destaca-se que no tocante aos efeitos benéficos do ato de amamentar, 98,1\% das alunas relataram ter conhecimento sobre o fortalecimento do vínculo afetivo entre a mãe e o bebê que a amamentação proporciona. Outrossim, 83,2\% acreditavam que há uma melhor recuperação pós-parto daquela mulher que amamenta.

Tabela 2 - Conhecimentos prévios das adolescentes nulíparas sobre a amamentação em duas escolas do município de Aracaju SE, 2018.

\begin{tabular}{|c|c|c|}
\hline Variáveis & $\mathbf{N}$ & $\%$ \\
\hline Definição de AM & 87 & 81,3 \\
\hline Importância do LM para o bebê & 107 & 100 \\
\hline \multicolumn{3}{|l|}{ Tempo mínimo de AME } \\
\hline Não existe & 15 & 14 \\
\hline 3 a 6 meses & 56 & 52,3 \\
\hline 7 a 12 meses & 31 & 29 \\
\hline Acima de 12 meses & 5 & 4,7 \\
\hline \multicolumn{3}{|l|}{ Foi amamentada quando criança } \\
\hline SIM & 98 & 91,6 \\
\hline NÃO & 5 & 4,6 \\
\hline NÃO SEI & 4 & 3,7 \\
\hline \multicolumn{3}{|l|}{$\begin{array}{l}\text { O AM fortalece o vínculo mãe- } \\
\text { bebê }\end{array}$} \\
\hline SIM & 105 & 98,1 \\
\hline NÃO & 2 & 1,9 \\
\hline \multicolumn{3}{|l|}{$\begin{array}{l}\text { A mulher que amamenta tem } \\
\text { uma melhor recuperação no } \\
\text { período pós-parto }\end{array}$} \\
\hline SIM & 89 & 83,2 \\
\hline NÃO & 18 & 16,8 \\
\hline
\end{tabular}

$\mathrm{N}=$ Número de adolescentes.

$\%=$ Porcentagem do número de adolescentes.

Fonte: banco de dados do próprio autor

No que concerne às crenças sobre o AM, 96,3\% das estudantes acreditavam que há mulheres que não conseguem produzir leite. Além disso, 81,3\% referiram que existe leite materno fraco e 67,3\% alegaram que a amamentação pode levar a queda dos seios. Em relação a alimentação complementar, $85 \%$ das participantes ressaltaram que o "gogó", ou seja, as fórmulas prontas, alimenta mais a criança que o leite materno e apenas, 36,4\% sinalizaram que a mamadeira e a chupeta atrapalham a amamentação (Tabela 3). 
Vale salientar que somente 8 (7,5\%) meninas tiveram acesso a algum tipo de atividade educativa sobre o aleitamento materno, sendo que o local mais frequente foi na escola $(3,7 \%)$, seguido pelo ambiente virtual $(1,9 \%)$ e por último, igualmente em unidade de saúde $(0,9 \%)$ e em casa $(0,9 \%)$. No entanto, $99,1 \%$ das alunas já presenciou o ato da amamentação em seus núcleos de convivência. Mesmo com esse déficit de acesso a informação, $85 \%$ das respondentes afirmaram ter a intenção de amamentar.

Tabela 3 - Crenças das adolescentes nulíparas sobre a amamentação em duas escolas do município de Aracaju - SE, 2018.

\begin{tabular}{|c|c|c|}
\hline Variáveis & $\mathbf{N}$ & $\%$ \\
\hline \multicolumn{3}{|c|}{$\begin{array}{l}\text { Crença: Existem mulheres que } \\
\text { não conseguem produzir leite }\end{array}$} \\
\hline SIM & 103 & 96,3 \\
\hline NÃO & 4 & 3,7 \\
\hline \multicolumn{3}{|c|}{ Crença: Existe leite fraco } \\
\hline SIM & 87 & 81,3 \\
\hline NÃO & 20 & 18,7 \\
\hline \multicolumn{3}{|c|}{$\begin{array}{c}\text { Crença: Amamentar causa a } \\
\text { queda das mamas }\end{array}$} \\
\hline SIM & 72 & 67,3 \\
\hline NÃO & 35 & 32,7 \\
\hline \multicolumn{3}{|c|}{$\begin{array}{l}\text { O "gogó" alimenta mais a } \\
\text { criança que o LM }\end{array}$} \\
\hline SIM & 91 & 85 \\
\hline NÃO & 16 & 15 \\
\hline \multicolumn{3}{|c|}{$\begin{array}{l}\text { A mamadeira ou chupeta } \\
\text { atrapalham a amamentação }\end{array}$} \\
\hline SIM & 39 & 36,4 \\
\hline NÃO & 68 & 63,6 \\
\hline \multicolumn{3}{|c|}{$\begin{array}{l}\text { Participou de atividades } \\
\text { educativas sobre AM }\end{array}$} \\
\hline SIM & 8 & 7,5 \\
\hline NÃO & 99 & 92,5 \\
\hline \multicolumn{3}{|c|}{ Local da atividade educativa } \\
\hline Escola & 4 & 3,7 \\
\hline Em casa & 1 & 0,9 \\
\hline Internet & 2 & 1,9 \\
\hline Unidade de saúde & 1 & 0,9 \\
\hline
\end{tabular}




\begin{tabular}{|c|c|c|}
\hline $\begin{array}{c}\text { Já presenciou alguém } \\
\text { amamentando }\end{array}$ & & \\
\hline SIM & 106 & 99,1 \\
\hline NÃO & 1 & 0,9 \\
\hline Tem intenção de amamentar & & 85 \\
\hline SIM & 91 & 15 \\
\hline NÃO & 16 & \\
\hline
\end{tabular}

$\mathrm{N}=$ Número de adolescentes.

$\%=$ Porcentagem do número de adolescentes.

Fonte: banco de dados do próprio autor

Na tabela 4, compara-se as respostas das estudantes da escola particular e da pública sobre alguns pontos que são favoráveis a prática do AM. Evidenciou-se que o conhecimento da definição de AM foi maior entre as alunas da instituição privada (87\%), além disso, houve um predomínio do histórico de amamentação na infância também entre as meninas desse grupo (94,4\%). Já a intenção de amamentar foi menor entre as alunas do colégio público (77,4\%). Não existiram diferenças importantes nas respostas dos outros parâmetros.

Tabela 4 - Comparação do conhecimento sobre AM entre as estudantes da escola particular e da pública de Aracaju - SE, 2018.

\begin{tabular}{|c|c|c|c|c|c|}
\hline Variáveis & $\begin{array}{l}\text { Particular } \\
\quad(\mathbf{N})\end{array}$ & $\%$ & $\begin{array}{l}\text { Pública } \\
\text { (N) }\end{array}$ & $\%$ & $\mathbf{p}$ \\
\hline Definição de $\mathbf{A M}^{2}$ & 47 & 87,0 & 40 & 75,5 & 0,125 \\
\hline $\begin{array}{c}\text { Importância do } \mathbf{L M} \\
\text { para o bebê }\end{array}$ & 54 & 100 & 53 & 100 & \\
\hline $\begin{array}{c}\text { Tempo mínimo de } \\
\text { AME }\end{array}$ & & & & & 0,247 \\
\hline Não existe & 7 & 13,0 & 8 & 15,1 & \\
\hline 3 a 6 meses & 26 & 48,1 & 30 & 56,5 & \\
\hline 7 a 12 meses & 17 & 31,5 & 14 & 26,4 & \\
\hline Acima de 12 meses & 4 & 7,4 & 1 & 1,9 & \\
\hline $\begin{array}{l}\text { Foi amamentada } \\
\text { quando criança }\end{array}$ & & & & & 0,519 \\
\hline SIM & 51 & 94,4 & 47 & 88,7 & \\
\hline NÃO & 2 & 3,7 & 3 & 5,7 & \\
\hline
\end{tabular}




\begin{tabular}{|c|c|c|c|c|c|}
\hline NÃO SEI & 1 & 1,9 & 3 & 5,7 & \\
\hline $\begin{array}{c}\text { O AM fortalece o } \\
\text { vínculo mãe-bebê }\end{array}$ & & & & & 0,243 \\
\hline SIM & 54 & 100,0 & 51 & 96,2 & \\
\hline NÃO & 0 & 0,0 & 2 & 3,8 & \\
\hline $\begin{array}{c}\text { A mulher que } \\
\text { amamenta tem uma } \\
\text { melhor recuperação no } \\
\text { período pós-parto }{ }^{2}\end{array}$ & & & & & 0,965 \\
\hline SIM & 45 & 83,3 & 44 & 83,0 & \\
\hline NÃO & 9 & 16,7 & 9 & 17,0 & \\
\hline $\begin{array}{c}\text { Já presenciou alguém } \\
\text { amamentando }^{1}\end{array}$ & & & & & 1,00 \\
\hline SIM & 53 & 98,1 & 53 & 100,0 & \\
\hline NÃO & 1 & 1,9 & 0 & 0,0 & \\
\hline $\begin{array}{l}\text { Tem intenção de } \\
\text { amamentar }^{2}\end{array}$ & & & & & 0,027 \\
\hline SIM & 50 & 92,6 & 41 & 77,4 & \\
\hline NÃO & 4 & 7,4 & 12 & 22,6 & \\
\hline
\end{tabular}

As características numéricas estão em média \pm dp. As características categóricas estão em n (\%).

${ }^{1}$ Teste exato de Fisher ${ }^{2}$ Teste t-Student para amostras independentes *Significativo a 5\%

$\mathrm{N}=$ Número de adolescentes.

$\%=$ Porcentagem do número de adolescentes

Fonte: banco de dados do próprio autor

Sobre as crenças relacionadas à amamentação, destaca-se que a maior parte do grupo das adolescentes de instituição pública afirmou que o AM leva a queda dos seios (77,4\%). Outrossim, a porcentagem de quem acha que o "gogó" alimenta mais o bebê que o LM $(96,2 \%)$ e de que a mamadeira/chupeta não atrapalham a amamentação também foi mais expressiva entre meninas da escola pública (Tabela 5). 
Tabela 5 - Comparação das crenças sobre AM entre as estudantes da escola particular e da pública de Aracaju - SE, 2018.

\begin{tabular}{|c|c|c|c|c|c|}
\hline Variáveis & $\begin{array}{l}\text { Particular } \\
\quad(\mathbf{N})\end{array}$ & $\%$ & $\begin{array}{l}\text { Pública } \\
\text { (N) }\end{array}$ & $\%$ & $\mathbf{p}$ \\
\hline $\begin{array}{c}\text { Crença: Existem } \\
\text { mulheres que não } \\
\text { conseguem produzir } \\
\text { leite }^{1}\end{array}$ & & & & & 1,00 \\
\hline SIM & 52 & 96,3 & 51 & 96,2 & \\
\hline NÃO & 2 & 3,7 & 2 & 3,8 & \\
\hline $\begin{array}{c}\text { Crença: Existe leite } \\
\text { fraco }^{2}\end{array}$ & & & & & 0,149 \\
\hline SIM & 41 & 75,9 & 46 & 86,8 & \\
\hline NÃO & 13 & 24,1 & 7 & 13,2 & \\
\hline $\begin{array}{c}\text { Crença: Amamentar } \\
\text { causa a queda das } \\
\text { mamas }^{2}\end{array}$ & & & & & $0,028 *$ \\
\hline SIM & 31 & 57,4 & 41 & 77,4 & \\
\hline NÃO & 23 & 42,6 & 12 & 22,6 & \\
\hline $\begin{array}{l}\text { O "gogó" alimenta mais } \\
\text { a criança que o LM" }\end{array}$ & & & & & $0,001 *$ \\
\hline SIM & 40 & 74,1 & 51 & 96,2 & \\
\hline NÃO & 14 & 25,9 & 2 & 3,8 & \\
\hline $\begin{array}{c}\text { A mamadeira ou } \\
\text { chupeta atrapalham a } \\
\text { amamentação }\end{array}$ & & & & & $0,033^{*}$ \\
\hline SIM & 25 & 46,3 & 14 & 26,4 & \\
\hline NÃO & 29 & 53,7 & 39 & 73,6 & \\
\hline
\end{tabular}

As características numéricas estão em média \pm dp. As características categóricas estão em n (\%).

${ }^{1}$ Teste exato de Fisher ${ }^{2}$ Teste t-Student para amostras independentes ${ }^{*}$ Significativo a 5\%

$\mathrm{N}=$ Número de adolescentes.

$\%=$ Porcentagem do número de adolescentes

Fonte: banco de dados do próprio autor 


\section{DISCUSSÃO}

O presente estudo observou que o perfil socioeconômico predominante das participantes foi composto por meninas de 16 a 18 anos, de etnia parda, solteiras, que residem com os pais, nascidas na capital do Estado, com renda familiar mensal média de até 2 salários mínimos, economicamente não ativas (desempregadas), que já concluíram o ensino fundamental e, no momento, cursavam o ensino médio. A maioria referiu que foi amamentada ao seio quando criança, cujo tempo médio foi de 18 meses.

No tocante ao conhecimento prévio sobre o AM, a maior parte das estudantes conheciam a sua definição, todas sabiam que o leite materno é benéfico para o desenvolvimento do bebê, além de ajudar a fortalecer o vínculo materno-infantil e ter um efeito positivo na recuperação pós-parto da nutriz. O intervalo de tempo mais assinalado para a manutenção do AME foi de três a seis meses e quase que a totalidade das participantes já presenciou alguém amamentando em seus núcleos de convivência. Todos esses fatores são importantes para o início e a manutenção da amamentação.

Em um estudo transversal, comparativo, que teve como universo gestantes e puérperas, foi-se evidenciado que as grávidas apresentavam menos conhecimento e, por conseguinte, mais dúvidas sobre o aleitamento materno. Uma possível explicação para esse fato foi a de que a puérpera, por já ter passado pela fase do pré-natal, recebeu assistência dos profissionais de saúde e orientações quanto a amamentação. Outro tópico observado foi que quanto menor a idade da mulher, menor era o conhecimento desta sobre a amamentação e, como consequência, menor duração do $\mathrm{AM}^{8}$.

Diante dessa pesquisa com gestantes e puérperas, percebe-se a relevância do desenvolvimento das ações de educação em saúde realizadas para meninas nulíparas com a finalidade de sanar as possíveis dúvidas sobre a amamentação antes mesmo da primeira gestação, para que quando esta venha a acontecer, a mulher sinta-se motivada e segura para amamentar.

Em relação ao acesso à atividades informativas sobre o aleitamento materno, $92,5 \%$ das participantes, do presente estudo, relataram que nunca participaram de palestras ou ações semelhantes que tenham tal objetivo. Fato esse, de grande relevância, pois demonstra uma falha, tanto nos ambientes escolar e familiar quanto nas unidades de saúde, no desenvolvimento de intervenções a fim de esclarecer sobre os benefícios do AM e desmistificar algumas crenças que ainda persistem e que podem ser fatores que influenciem negativamente a prática da alimentação natural.

No que diz respeito as crenças, constatou-se que ainda há uma persistência entre as alunas na afirmação da existência do leite materno fraco, de que a amamentação leva a queda dos seios da nutriz, da superioridade nutricional da alimentação artificial para o lactente e de que a mamadeira ou chupeta não atrapalham o aleitamento. Tais valores, são perpetuados entre as gerações e podem ser prejudiciais ao processo de lactação. 
Uma pesquisa desenvolvida por Silva e Moraes, em 2011, teve como objetivo a caracterização de parturientes adolescentes, na qual verificou-se que a maioria das entrevistadas $(63,8 \%)$ conheciam o período de seis meses para o AME, porém 61,7\% delas não participaram durante o pré-natal de qualquer ação educativa ou de incentivo a amamentação. Além disso, notou-se também que 53,2\% das parturientes acreditavam que há mães que não produzem leite, e 44,7\% delas de que amamentar causa a queda dos seios, o que demonstra a deficiência de conhecimentos precisos sobre a alimentação natural ${ }^{6}$.

Dados esses, semelhantes aos do presente trabalho, no qual foi demonstrado uma deficiência, desde o período escolar, de atividades que visem transmitir informações sobre o AM. Apenas 7,5\% das alunas tiveram acesso a algum tipo de ação educativa sobre a amamentação e, por conseguinte, 96,3\% das estudantes referiram que há mulheres que não conseguem produzir leite, 81,3\% que existe leite materno fraco e $67,3 \%$ alegaram que a amamentação pode levar a queda dos seios. Além disso, 85\% das meninas assinalaram que a alimentação artificial é mais efetiva que a natural e apenas $36,4 \%$ delas, consideraram que a mamadeira ou chupeta fossem nocivas ao processo de amamentação.

Esses dados corroboram a relação entre a deficiência da quantidade de práticas educativas associado a perpetuação das crenças e, como consequência, reduzidas taxas de aleitamento materno e elevadas do desmame precoce.

Na presente pesquisa, percebeu-se também que apesar da persistência das crenças errôneas sobre o leite materno associada ao déficit de acesso a ações educativas, $85 \%$ das participantes relatou ter a intenção de amamentar. Circunstância essa, que pode ser justificada pelas experiências positivas relacionadas ao AM das participantes. Cerca de $99 \%$ delas referiu já ter presenciado alguém amamentando, 83,2\% afirmou que o AM auxilia a uma melhor recuperação pós-parto da nutriz e 98\% acredita que a lactação fortalece o vínculo materno-infantil.

Em uma recente revisão da literatura acerca das abordagens sobre a promoção do aleitamento materno no ensino fundamental, verificou-se que o conteúdo é abordado de forma superficial nos livros didáticos, o que pode gerar uma dificuldade e insegurança dos docentes em ministrar esse tema em sala de aula ${ }^{9}$. Em virtude disso, os alunos irão apresentar uma deficiência em relação aos conhecimentos sobre a lactação, podendo ter um impacto negativo sobre tal prática.

Em estudo realizado por Pereira e Grosseman, foi se observado que após uma intervenção pedagógica, ou seja, aulas teóricas e práticas sobre o aleitamento materno, os estudantes analisados tiveram um maior conhecimento sobre tal tema, em detrimento daqueles que não passaram por essa intervenção. Por conseguinte, o primeiro grupo tende a ter mais sucesso na prática do aleitamento natural ${ }^{10}$.

Galvão e Silva, em 2011, analisaram as experiências com o processo de amamentação de 1.800 crianças brasileiras que cursavam o $4^{\circ}$ e $5^{\circ}$ anos do Ensino Fundamental e tinham de 9 a 15 anos de idade. Eles verificaram que $90,2 \%$ dos estudantes sabiam ter sido amamentados e que a média de tempo da 
amamentação foi de 11,37 meses. A maioria dos participantes $(81,5 \%)$ considerou que o leite materno é a melhor fonte nutricional para o bebê e que o ato de amamentar aproxima a mãe do filho (56,9\%). A noção de que a amamentação leva a queda dos seios foi referida por apenas 14,9\% e 81\% relataram que gostaria, no futuro, de amamentar seu filho. Observou-se também que na escola que essas crianças frequentavam, para 83,9\% delas, não existia qualquer desenho, fotografia ou cartaz que abordassem o $\mathrm{AM}^{11}$.

No presente trabalho a média de tempo de amamentação referida pelas alunas de ambas as escolas foi de 18 meses, e aproximadamente $94 \%$ das estudantes do ensino particular e $88 \%$ das estudantes do ensino público afirmaram ter sido amamentadas quando crianças. A melhor fonte nutricional declarada pelas participantes foi o leite artificial, referida por $74,1 \%$ das meninas do colégio particular e por $96,2 \%$ do público e, no tocante a relação entre o AM e a queda dos seios da mulher, 57,4\% das respondentes do ensino privado e 77,4\% das participantes do ensino público, a consideram verdadeira. Fatos esses, discordantes dos achados na pesquisa de Galvão e Silva ${ }^{11}$.

No Brasil, dois outros estudos avaliaram o conhecimento de estudantes do ensino fundamental sobre a amamentação. Nas duas experiências, os resultados demonstraram que quanto maior o conhecimento sobre o AM adquirido pelos participantes, maior o efeito positivo sobre tal prática ${ }^{12,13}$. A maior parte $(87,1 \%)$ dos estudantes referiu ter recebido alguma informação sobre o aleitamento materno prévia, sendo os meios de comunicação os maiores disseminadores do tema, seguidos pela escola ${ }^{13}$.

Esse fato é discordante dos achados do presente trabalho, pois apenas a minoria $(7,5 \%)$ das participantes afirmou ter recebido algum tipo de informação prévia sobre a lactação e a escola foi o ambiente mais citado (3,7\%). O ambiente virtual foi assinalado por 1,9\% das participantes, já o familiar e as unidades de saúde foram assinalados por apenas uma participante $(0,9 \%)$, cada.

Em uma pesquisa transversal e descritiva realizada com 100 alunos do terceiro ano do ensino médio, de uma escola pública do interior de Pernambuco, sobre o conhecimento prévio relacionado ao AM, verificou-se que $56 \%$ da amostra assinalou ter conhecimento sobre tal tema. As principais fontes de conhecimento sobre a amamentação, segundo os alunos, foram os familiares, amigos ou a escola citados por $37,9 \%$. O período mínimo de AME que a criança deve receber referido por $65 \%$ dos participantes foi até os seis meses.

No tocante às crenças, $51 \%$ dos respondentes afirmaram que o aleitamento materno leva a queda dos seios da nutriz e $68 \%$ acreditam na existência do leite materno fraco ${ }^{14}$.

$\mathrm{Na}$ atual pesquisa, verificou-se que $87 \%$ das estudantes do ensino particular sabiam a definição de AM, já as do ensino público, o percentual foi de 75,5\%. O intervalo mínimo de AM mais referido pelos dois grupos de estudantes foi de 3 a 6 meses. Em relação as crenças, os resultados foram semelhantes ao do estudo citado, constatando-se que a maioria das estudantes das duas escolas acreditam que a lactação está relacionada a queda dos seios maternos (57,4\% das respondentes do ensino particular e $77,4 \%$ do 
ensino público) e aproximadamente $96 \%$ de ambas as instituições referiram que há mães que não produzem leite. Além dessas assertivas, $75,9 \%$ das alunas da escola particular e $86,8 \%$ das estudantes do ensino público afirmaram a existência do leite materno fraco.

Nakamura et. al., em 2003, realizou um trabalho, no qual foi comparado as diferentes percepções sobre o AM das estudantes de escolas pública e particular, de um interior de São Paulo. O universo da pesquisa foi composto por 346 meninas, sendo que 149 eram alunas do ensino particular e 197 do público. Observou-se que a faixa etária mais prevalente foi entre 9 a 15 anos, aproximadamente $98 \%$ das respondentes já presenciou alguma mãe amamentando, além disso, 90\% referiu ter sido amamentadas. Mais de $80 \%$ revelou o desejo de amamentar seus filhos, no futuro. Todavia, $46 \%$ das estudantes do ensino particular e 32\% do ensino público afirmaram ter vergonha de amamentar em público, esse fato indica que o ato de amamentar não é considerado uma atitude totalmente natural por essas meninas. Em torno de $90 \%$ das participantes consideram o leite humano como o melhor alimento para o lactente, porém perto de $60 \%$ delas ofereceria chupeta para o bebê. Foi verificado um maior percentual entre as alunas da instituição privada que optaram pelo $\operatorname{AME~}(\mathrm{p}=0,02)$ em comparação com as alunas da instituição pública ${ }^{15}$.

Comparando-se os resultados entre a instituição de ensino particular e a pública analisados na presente pesquisa, notou-se que a maioria das participantes de ambos os grupos tinham conhecimento sobre definição de aleitamento materno e todas (100\%) acreditavam na importância do leite materno para a criança. Outro dado relevante foi no que diz respeito ao tempo mínimo de AM, houve uma concordância entre os dois grupos na prevalência do período de três a seis meses. Além disso, a maioria das respondentes, das duas escolas, foram amamentadas quando criança e, apenas $1(1,9 \%)$ participante da escola particular afirmou não ter presenciado em um dos seus núcleos de convivência alguém amamentando. Todos esses pontos ressaltados podem contribuir para a futura prática da alimentação natural por essas nulíparas.

No que diz respeito as crenças das participantes, verificou-se que as estudantes da instituição pública associaram mais o ato de amamentar a queda dos seios maternos $(77,4 \%)$ em comparação com as da escola particular, cujo percentual foi de 57,4\%. Em relação a eficácia da alimentação artificial (“gogó”) e ao uso da chupeta/mamadeira pelo lactente, também houve uma maior defesa entre as estudantes do ensino público. Existiu uma concordância entre os dois grupos de que algumas mulheres não produzem o leite materno. A crença do leite fraco foi maior entre as participantes da instituição pública $(86,8 \%)$, em detrimento da particular $(75,9 \%)$.

Esses fatos descritos, podem ter um impacto negativo sobre o ato futuro de amamentar, por conseguinte, já se foi verificado, no presente estudo, um menor índice na intenção de amamentar entre as estudantes da escola pública (77,4\%), comparando-se com as da escola particular (92,6\%).

É importante ressaltar que, na revisão de literatura realizada para o desenvolvimento do presente estudo, foram encontrados poucos trabalhos que tenham estabelecido uma comparação do prévio 
conhecimento de adolescentes nulíparas sobre a amamentação entre estudantes de escola pública e particular, demonstrando assim, a necessidade de mais pesquisas acerca do tema.

\section{CONCLUSÃO}

Os resultados encontrados no presente trabalho sugerem que mesmo com o acesso restrito a atividades educativas sobre o aleitamento materno, as participantes apresentaram conceitos positivos sobre tal prática e, como consequência a intenção de amamentar. Entretanto, ainda há uma perpetuação dos mitos e crendices que podem prejudicar a futura prática da alimentação natural por essas meninas.

Diante do exposto, é necessário que haja um incentivo, não só no ambiente escolar, como também nas unidades de saúde, e em domicílios, a realização de ações informativas, com o objetivo de sanar as dúvidas e desmistificar alguns pontos sobre a amamentação, direcionados as crianças e aos adolescentes, para que no futuro tenhamos uma elevação das taxas de amamentação e uma queda no desmame precoce.

Além disso, salienta-se também a necessidade de que os trabalhos voltados ao apoio, proteção e promoção da amamentação não sejam direcionados apenas as mulheres, mas também aos familiares e sociedade em geral, com a finalidade de garantir à saúde materno-infantil. 


\section{REFERÊNCIA BIBLIOGRÁFICA}

BRASIL. Ministério da Saúde. Secretaria de Atenção à Saúde. Departamento de Atenção Básica. SAÚDE DA CRIANÇA: Aleitamento Materno e Alimentação Complementar. Brasília: Ministério da Saúde; 2015, $2^{a}$ edição, Cadernos de Atenção Básica, no 23;

BRASIL. Ministério da Saúde. Secretaria de Atenção à Saúde. Departamento de Ações Programáticas e Estratégicas. Atenção à saúde do recém-nascido: guia para os profissionais de saúde: cuidados gerais. Brasília: Ministério da Saúde; 2013. v. 1. 95-105p. (Série A. Normas e Manuais Técnicos);

BRASIL. II Pesquisa de Prevalência do Aleitamento Materno nas Capitais Brasileiras e Distrito Federal. Brasília, 2009/2010;

World Health Organization. Maternal, newborn, child and adolescent health. Breastfeeding [homepage on the Internet] [cited April 2018]. Available from: http://www. who.int/maternal_child_adolescent/topics/child/nutrition/breastfeeding/en/. Acess in: April 2018.

TETER, M.S.H., OSELAME, G.B., NEVES, E.B. Amamentação e desmame precoce em lactantes de Curitiba. Revista Espaço para a Saúde, 2016; 16(4): 55-63;

SILVA, S.P., MORAES, M.S. Caracterização de parturientes adolescentes e de seus conhecimentos sobre amamentação. Arq Ciênc Saúde, 2011; 18(1):28-35;

SANTOS, M.P., SANTANA, M.S., OLIVEIRA, D.S., FILHO, R.A.N., LISBOA, C.S., ALMEIDA, L.M.R., GOMES, D.R., QUEIROZ, V.A.O., DEMÉTRIO, F., OLIVEIRA, A.M. Prevalência e fatores associados à interrupção precoce do aleitamento materno exclusivo: metanálise de estudos epidemiológicos brasileiros. Rev. Bras. Saúde Matern. Infant., 2017; 17 (1): 69-78;

CASTELLI, C.T.R., MAAHS, M.A.P., ALMEIDA, S.T. Identificação das dúvidas e dificuldades de gestantes e puérperas em relação ao aleitamento materno. Rev. CEFAC, 2014; 16(4):1178-118;

MARTINS, F.D.P., LEAL, L.P., GUEDES, T.G., JAVORSKY, M., PONTES, C.M. Promoção do aleitamento materno no ensino fundamental: revisão integrativa. Revista Eletrônica de Enfermagem, Goiânia, v. 18, dez. 2016. ISSN 1518-1944. Disponível em: <https://revistas.ufg.br/fen/article/view/40682/22158>. Acesso em: $05 \quad$ maio 2018. doi:https://doi.org/10.5216/ree.v18.40682;

PEREIRA, D.N., GOSSEMAN, S. Impacto de uma intervenção pedagógica no conhecimento do aleitamento materno. Revista da AMRIGS, 2013; 57 (1): 14-20;

GALVÃO, D.M.P.G., SILVA, I.A. Conhecendo as vivências de amamentação da criança brasileira que frequenta o ensino fundamental. Rev. Eletr. Enf. [Internet]. 2011 jul/set;13(3):377-85. Disponível em: <http://www.fen.ufg.br/revista/v13/n3/v13n3a03.htm>. Acesso em: 05 maio 2018;

BOTTARO, S.M., GIUGLIANI E.R.J. Effectiveness of an intervention to improve breastfeeding knowledge and attitudes among fifth-grade children in Brazil. J Hum Lact. 2009; 25(3):325-332;

FUGIMORI, M., MORAIS, T., FRANÇA, E.L., TOLEDO, O.R., HONÓRIO-FRANÇA, A.C. The attitues of primary school children and the effect of health education lectures. J Pediatr, 2008; 84(3):224-231; 
CÉSAR, E.C., BARROS, E.S., ALVES, J.N. Conhecimento de estudantes do ensino médio sobre amamentação. Revista Tema, 2013; 14 (20/21);

NAKAMURA, S.S., VEIGA, K.F., FERRARESE, S.R.B., MARTINEZ, F.E. Percepção e conhecimento de meninas escolares sobre o aleitamento materno. Jornal de Pediatria, 2003; 79(2); 